\title{
Tara Gum as a Controlled Delivery System of Fluoride in Toothpaste: In Vitro Enamel Remineralization Study
}

\author{
Nayanna Lana Soares Fernandes ${ }^{1}$, Ingrid Andrade Meira ${ }^{2}$, , Vanessa Feitosa Alves ${ }^{1}(\mathbb{0}$, Fabio \\ Correia Sampaio $^{1}$, Andressa Feitosa Bezerra de Oliveira ${ }^{3}$
}

\begin{abstract}
'Department of Clinic and Social Dentistry, School of Dentistry, Federal University of Paraíba, João Pessoa, PB, Brazil. ${ }^{2}$ Department of Prosthesis and Periodontics, Piracicaba Dental School, University of Campinas, Piracicaba, SP, Brazil. ${ }^{3}$ Department of Morphology, School of Dentistry, Federal University of Paraíba, João Pessoa, PB, Brazil.
\end{abstract}

Correspondence: Nayanna Lana Soares Fernandes, Departamento de Clínica e Odontologia Social, Curso de Odontologia, Centro de Ciências da Saúde, Campus I, Universidade Federal da Paraíba, João Pessoa, PB, Brazil. 58.05 1-900. E-mail: naaah.soares.fernandes@hotmail.com

Academic Editor: Alessandro Leite Cavalcanti

Received: 09 March 2020 / Review: 20 April 2020 / Accepted: 26 June 2020

How to cite: Fernandes NLS, Meira IA, Alves VF, Sampaio FC, Oliveira AFB. Tara gum as a controlled delivery system of fluoride in toothpaste: in vitro enamel remineralization study. Pesqui Bras Odontopediatria Clín Integr. 2021; $21: e 0046$. https://doi.org/10.1590/pboci.2021.003

\begin{abstract}
Objective: To evaluate the remineralizing potential of a hydrocolloid-based, controlled fluoride-releasing system added to dentifrice formulas. Material and Methods: Sixty-five human enamel blocks were prepared and the surface microhardness ( $\mathrm{SHO}$ ) values were determined. The artificial caries lesions were induced and the demineralization surface microhardness ( $\mathrm{SH} 1)$ was evaluated. The blocks were randomly allocated into five groups $(\mathrm{n}=13)$ : (1) 100-TGF (100\% NaF with Tara gum added); (2) $50-\mathrm{TGF}$ (50\% free $\mathrm{NaF}+50 \% \mathrm{NaF}$ with Tara gum added); (3) $100 \% \mathrm{TG}$ (100\% Tara gum without fluoride); (4) $100 \% \mathrm{NaF}$ (positive control); and (5) placebo (without Tara gum and $\mathrm{NaF}$ ). The blocks were submitted to 7 days $\mathrm{pH}$ cycling and treated with dentifrice slurries twice a day. Finally, surface hardness ( $\mathrm{SH} 2)$ was assessed and the percentage of surface hardness recovery (\%SMHR) was calculated. Analysis of variance (ANOVA) followed by Bonferroni test was used for statistical analysis. Results: A positive \%SMHR was found in the $100 \% \mathrm{NaF}$ (5.07) and 50-TGF (0.64) groups, while the 100-TGF (-1.38), 100\% TG (-3.88) and placebo (-0.52) did not undergo remineralization. Statistically significant differences were observed between $100 \% \mathrm{NaF}$ and all the groups except for 50-TGF ( $\mathrm{p}<0.05$ ). Conclusion: The presence of hydrocolloid (Tara gum) promoted minimal remineralization when associated with $\mathrm{NaF}$. In the applied model, Tara gum may have compromised remineralization, preventing free fluoride from acting effectively in the carious lesion.

Keywords: Biomedical and Dental Materials; Polymers; Dentifrices; Toothpastes; Fluoride.
\end{abstract}




\section{Introduction}

The use of fluoride toothpastes is considered the most effective and most performed method of dental caries reduction [1-3]. It is a convenient, cost-effective, and culturally approved method that is widespread throughout the world, making it an ideal public health method [4]. Its favorable performance can be attributed to the combination of topical fluoride exposure and mechanical disruption of dental biofilms [1,3].

The maintenance of an appropriate intraoral fluoride concentration is a desire; however, it is not an easy task due to its rapid clearance in oral fluids [5]. The decrease of salivary fluoride after brushing with a fluoride dentifrice can occur in two different phases: (A) a rapid disappearance from the mouth, lasting 40-80 min and varying in each individual, and (B) a slow elimination, lasting for several hours [5]. In addition, products that use new technologies for the slow release of fluoride and its long-lasting maintenance in the oral cavity have caught the attention of researchers [6]. For example, the addition of hydrocolloids to the toothpaste composition has been suggested as a controlled fluoride-releasing system [7].

Hydrocolloids are composed of polysaccharides, which are obtained from a wide variety of natural and renewable sources such as plants, microorganisms, and animals. They have attracted the attention of several industrial fields due to their favorable properties, including biocompatibility, biodegradability, low cost, and abundance in nature [8]. The majority of hydrocolloids are widely used in the food, pharmaceutical, and cosmetics industries as thickeners, texture modifiers, emulsifiers, stabilizers, and gelling agents [8-10].

Recently, the hydrocolloid Tara gum, also named as Peruvian carob, has received great attention from the pharmaceutical and cosmetics industries. As reported by some studies [11,12], it has the potential to act as a controlled-release system for drugs (tablets and emulsions). Tara is a natural gum that can be obtained in powder form by grinding the seed endosperm of the Caesalpinia spinosa tree. The aim of this study was to evaluate the remineralization potential of fluoride dentifrices containing Tara gum, as a promising controlledrelease system of fluoride, on early enamel caries. To the best of our knowledge, the present research is the first in vitro study to evaluate the remineralizing capacity of fluoride dentifrices containing Tara gum for the treatment of dental caries.

\section{Material and Methods}

Study Design

This study was a randomized, double-blind trial using teeth that were submitted to a pH-cycling model.

Preparation of Enamel Samples and Lesion Formation

Enamel blocks $(4 \times 4 \times 2 \mathrm{~mm})$ were obtained from human permanent third molar teeth that were stored in $2 \%$ formaldehyde solution, $\mathrm{pH}$ 7.0, for 30 days at room temperature.

To calculate the sample size, a beta error of $10 \%$, and an alpha error of $5 \%$, statistical power of $80 \%$ and an average magnitude of 0.5 were considered. The calculation was made using excel software, according to the equation below, to reach an $n$ with $80 \%$ power $\left(Z_{1-\beta}=0.846\right)$. The addition of $10 \%$ of sample loss in the value resulted in a sample of $75\left(\mathrm{n}=15\right.$ per group), where $Z_{1-} \beta$ represents the beta error, $\mathrm{d}$ is the effect magnitude, $\mathrm{n}$ is the sample number and $Z_{1-\alpha}$ is the alpha error

Equation 1: $Z_{1}-\beta=d(n-1) \sqrt{2 n} / 2(n-1)+1.21\left(Z_{1}-\alpha-1.06\right)-Z_{1}-\alpha$ 
The specimens were embedded in acrylic resin, and the enamel surface was ground flat with watercooled carborundum discs (300, 400, 600, 1200 grades) under constant irrigation. Next, the specimens were polished by a felt paper wet by a $1-\mu \mathrm{m}$ diamond suspension. Three indentations spaced $100 \mu \mathrm{m}$ from each other were made at the center of the enamel surface. The baseline surface microhardness (SHo) values of the enamel were determined by a Shimadzu HMV-AD microhardness tester with a Vickers diamond under a 100-g load for 10s. All specimens' surfaces, except the enamel area of $16 \mathrm{~mm}^{2}$, were coated with an acid-resistant varnish.

Then, the samples were subjected to artificial caries lesion formation by immersion in $32 \mathrm{~mL}$ of demineralizing solution containing $1.3 \mathrm{mM} \mathrm{Ca}\left(\mathrm{NO}_{3}\right)_{2} \cdot 4 \mathrm{H}_{2} \mathrm{O}, 0.78 \mathrm{mM} \mathrm{NaH} 2 \mathrm{PO} 4 \cdot \mathrm{H}_{2} \mathrm{O}$, $0.05 \mathrm{M}$ acetate buffer,

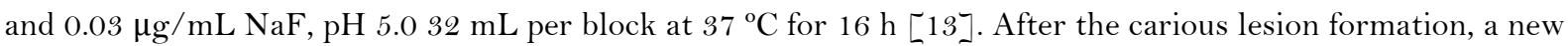
surface microhardness ( $\mathrm{SH} 1$ ) was measured for the demineralization area.

pH Cycling and Treatment

The blocks of human tooth enamel $(4 \times 4 \times 2 \mathrm{~mm})$ were allocated into the following five groups $(\mathrm{n}=15)$ : (1) $100-\mathrm{TGF}(100 \% \mathrm{NaF}$ with Tara gum added); (2) 50 -TGF ( $50 \%$ free $\mathrm{NaF}+50 \% \mathrm{NaF}$ with Tara gum added); (3) 100\% TG (100\% Tara gum without fluoride); (4) 100\% NaF (positive control, free NaF and without Tara gum); and (5) placebo (without Tara gum and NaF) (Savoy SA, São Paulo, SP, Brazil). All experimental dentifrices included the following ingredients: water, carboxymethyl cellulose (binder), sodium lauryl sulfate (surfactant), hydrated silica (abrasive), 70\% sorbitol and glycerin (humectants), and methylparaben (preservative). The $\mathrm{pH}$ of the dentifrices was controlled by disodium phosphate [7].

An independent researcher, who was not involved in this in vitro study, labeled all dentifrices. The toothpastes were packed in similar tubes $(60 \mathrm{~g})$ and had the same characteristics (color, packing, consistency, and flavor). All of the fluoride dentifrices contained $1.100 \mathrm{ppm}$ fluoride $(\mathrm{mg} \mathrm{F} / \mathrm{g}$ ), with the exception of the $100 \%$ TG and placebo groups. The experimental dentifrices had a maximum of $6 \%$ Tara gum in their formulation, based on the previous study [7].

A pH-cycling model at $37^{\circ} \mathrm{C}$ during 7 days was subjected, individually, to each enamel especimen. The samples were cycled between a remineralizing solution $(1.5 \mathrm{mM} \mathrm{Ca}, 0.9 \mathrm{mMP}, 0.15 \mathrm{MKCl}, 0.05 \mathrm{ppm} \mathrm{F}, 0.02 \mathrm{M}$ cacodylate buffer, $\mathrm{pH} 7.0 ; 1.11 \mathrm{~mL} / \mathrm{mm}^{2}$ of enamel surface) for $18 \mathrm{~h}$ and a demineralization solution $(2.0 \mathrm{mM}$ $\mathrm{Ca}, 2.0 \mathrm{mM} \mathrm{P}, 0.04 \mathrm{ppm} \mathrm{F}$, and $0.075 \mathrm{M}$ acetate buffer, $\mathrm{pH} 4.7 ; 2.22 \mathrm{~mL} / \mathrm{mm}^{2}$ of enamel surface) for $6 \mathrm{~h}$ during 5 days. The next 2 days, the blocks were kept in remineralization solution [14]. The solutions were changed daily. The treatment consisted of 1-min soaks slurries for all specimens ( $2 \mathrm{~mL} / \mathrm{block}$ ) of each toothpaste group diluted in deionized water (1:3). The treatments were performed twice a day (before and after the demineralizing period) under agitation [14].

\section{Microhardness Analysis}

The surface microhardness was determined using a microhardness tester (Shimadzu HMV-AD Easy Test Version 3.0, Tokyo, Japan) with a Vickers diamond under a 100-g load for 10s. After the pH cycling and treatment, the surface microhardness was measured again ( $\mathrm{SH} 2$ ). Three indentations spaced $100 \mu \mathrm{m}$ from each other and from the baseline were made. Finally, the percentage of surface hardness recovery (\%SMHR) was calculated according to equation 2:

Equation 2: $\%$ SMHR $=((\mathrm{SH} 2-\mathrm{SH} 1) /(\mathrm{SHo}-\mathrm{SH} 1)) \times 100$ 
Statistical Analyses

The SPSS program was used for statistical analyses and $\mathrm{p}<0.05$ indicates statistical significance. The data presented a normal distribution (Shapiro-Wilk). Analysis of variance (ANOVA), followed by Bonferroni test, was used to compare $\mathrm{SH}, \mathrm{SH} 1, \mathrm{SH} 2$ and \% $\mathrm{SMHR}$ into the same group and between groups.

Ethical Clearance

The protocol of this study was approved by the Brazilian Ethics Committee for Research with Human Beings (CAAE: 45917915.6.0000.5188).

\section{Results}

The statistical analysis after the treatment took into account a size of 13 specimens per group. Variations in some groups forced the elimination of two samples, one with the highest and another with lowest values of each group. This loss was found within the safety margin made by the sample calculation of $10 \%$ of extra samples.

The mean of each group between the three periods are described in Table 1. No statistical differences were observed between the groups for SHo. Differences were observed between groups for $\mathrm{SH}_{1}$ and $\mathrm{SH} 2$ variables. The greater remineralization recovery was observed on $100 \% \mathrm{NaF}$ group (positive control).

Table 1. Mean and standard deviation (SD) of SHo, $\mathrm{SH} 1$ and $\mathrm{SH} 2$ from all the tested groups.

\begin{tabular}{cccc}
\hline Groups & SHo $($ SD $)$ & SH1 $($ SD $)$ & SH2 $($ SD $)$ \\
\hline $100 \%$ TG & $355.67( \pm 8.65)^{\mathrm{a}}$ & $49.94( \pm 20.70)^{\mathrm{b}}$ & $39.14( \pm 8.05)^{\mathrm{a}, \mathrm{b}}$ \\
$50-\mathrm{TGF}$ & $373.94( \pm 10.67)^{\mathrm{a}}$ & $16.73( \pm 7.16)^{\mathrm{a}}$ & $19.04( \pm 8.61)^{\mathrm{c}}$ \\
$100-\mathrm{TGF}$ & $376.92( \pm 4.06)^{\mathrm{a}}$ & $30.96( \pm 12.61)^{\mathrm{a}, \mathrm{b}}$ & $26.63( \pm 10.20)^{\mathrm{b}, \mathrm{c}}$ \\
$100 \% \mathrm{NaF}$ & $374.56( \pm 8.72)^{\mathrm{a}}$ & $29.38( \pm 28.78)^{\mathrm{a}, \mathrm{b}}$ & $47.54( \pm 21.51)^{\mathrm{a}}$ \\
Placebo & $389.73( \pm 10.18)^{\mathrm{a}}$ & $27.77( \pm 7.24)^{\mathrm{a}}$ & $26.10( \pm 8.47)^{\mathrm{b}, \mathrm{c}}$ \\
\hline Distinct letters in each variable, means statistical significance difference between the groups in the column $($ ANOVA, p<0.05).
\end{tabular}

The mean \%SMHR values of all groups from the highest to the lowest were as follows: $100 \% \mathrm{NaF}$ $(5.07)>50-$ TGF $(0.64)>$ placebo $(-0.52)>100-$ TGF $(-1.38)>100 \%$ TG (-3.88). No statistical difference was observed between the Placebo and all the dentifrices containing Tara gum $(\mathrm{p}>0.05)$. The positive control was different from all the groups, except the 50-TGF dentifrice, as shown on Figure 1.

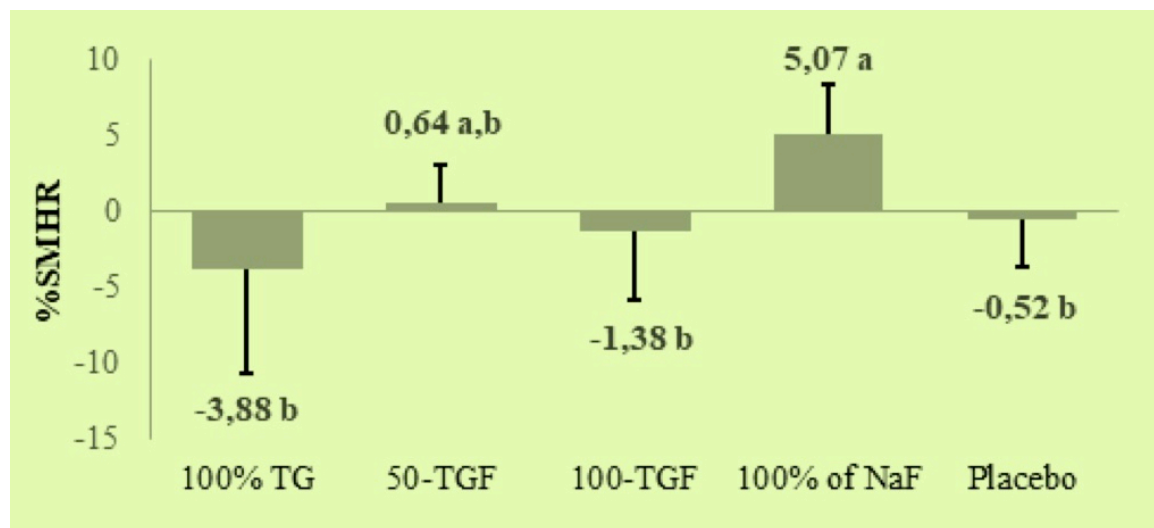

*Different letters indicate statistical differences between groups. ANOVA test followed by Tukey's test $(\mathrm{p}<0.05)$.

Figure 1. Mean and standard deviation of \%SMHR of initial carious lesions treated with different experimental dentifrices containing fluoride associated with Tara gum. 


\section{Discussion}

The effect of fluoride on dental caries control is highly dependent on its clearance rate by saliva. New products that provide a slow release of fluoride and facilitate its long-lasting maintenance in the oral cavity have been developed [6]. In addition, hydrocolloids have been investigated due to their biocompatibility, biodegradability, and ability to modify the rheology of the system where they are used [8].

In this study, the controlled release system of fluoride based on Tara gum was chosen due to the experience of our research group that found the release of fluoride and a reasonable long-lasting effect on the substantivity of fluoride in this system. However, the remineralizing effect was not studied [7]. Therefore, the aim of this in vitro study was to evaluate the remineralizing potential of fluoride dentifrices containing Tara gum as a fluoride-releasing delivery system in the treatment of dental caries.

Initially, based on previous study performed by our research group [7], it was believed that fluoride dentifrices with Tara gum would increase the time of availability of fluoride on the enamel surface and it would act as a promising controlled-release system of fluoride. However, this behavior of the experimental group 100TGF was not observed as expected.

In fact, the Tara gum associated with fluoride was not able to remineralize lesions effectively, resulting in discrete remineralization in the 50-TGF group and mineral loss in the 100-TGF and $100 \%$ TG. This finding suggests that the fluoride incorporated into the Tara gum might not be immediately available to act in remineralization. It is likely that the behavior of these experimental dentifrices with Tara gum can be linked to their mechanical characteristics, such as (A) stable viscosity over a wide pH range (pH 3-11) [11] which decreases with the increase of temperature from $20^{\circ} \mathrm{C}$ to $80^{\circ} \mathrm{C}[10]$; (B) adhesive capacity; and (3) ability to form films on surfaces [6].

Therefore, the results suggest that the Tara gum produced a physical barrier that prevented the incorporation of free fluoride ions into the enamel. Support for this physical barrier theory is provided by potentiometric measurements of dental products containing hydrocolloids. Erratic readings of ion-specific electrodes (ISEs) have been performed due to the physical barrier produced by the Tara gum [7]. This barrier avoids the contact between the analyte and the sensing membrane of the electrode. In fact, to reduce the risk of errors with ISEs, a list of interferences has been reported for laboratory precautions [15]. Among these interferents, herbal medications, natural products, and surfactants are listed [15]. Based on these facts, the Tara gum appeared to be linked to fluoride during cycling, preventing its release to act in the remineralization process. The dentifrices with more Tara gum had the worst remineralization values.

This research used a well-established in vitro pH-cycling model and treatment conditions close to those of the oral cavity to evaluate the behavior of new fluoride toothpastes [16]. In spite of this, it was found to have a high standard deviation, however, it is a common finding [17-19] in the literature for this type of study. This was probably due to tissue variation in the enamel specimens and to minimize this problem two samples of each group were eliminated, which were within the safety margin. It is important to note that the lack of saliva, acquired pellicle, the mechanical action of tooth brushing' and the presence of biofilm in the in vitro remineralizing $\mathrm{pH}$-cycling models limits the in vitro results to compare with the clinical context [20].

The salivary enzymes could have contributed to the F-release in this in vitro system in the remineralization performance of the experimental dentifrices groups. However, precautions were applied to guarantee the minimal influence of external variables in the model, since this was the first in vitro study to evaluate the remineralizing capacity of fluoridated dentifrices with Tara gum, as a controlled system for fluoride release. Hence, the most important result of this experimental study is the understanding that a 
fluoride-hydrocolloid system may not represent an additional benefit to the remineralizing process. It can be hypothesized that once fluoride is associated with hydrocolloids it might not be promptly released.

Finally, the data obtained from this research increased the knowledge regarding fluoride-hydrocolloid (Tara gum) systems. Using this in vitro remineralizing $\mathrm{pH}$ cycling model, it is believed that fluoride ions were not available to act in the remineralization process when associated with Tara gum. Thus, we believe that given the properties of the Tara Gum system, new formulations, and new ways of delivery systems can be studied. A modified in vitro study and in vivo trial may provide better oral conditions and allow the fluoride release to happen more effectively.

\section{Conclusion}

The fluoride-hydrocolloid system added to dentifrices formulas did not offer any advantage for this in vitro artificial carious lesion remineralization. The presence of hydrocolloid (Tara gum) promoted minimal remineralization when associated with $\mathrm{NaF}$. In the applied model, Tara gum may have compromised remineralization, preventing free fluoride from acting effectively in the carious lesion recovery.

\section{Authors' Contributions}

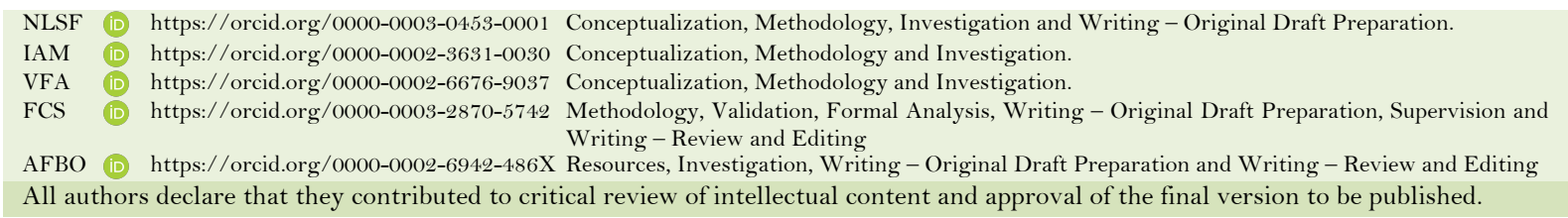

\section{Financial Support}

The National Council supported the work for Scientific and Technological Development (CNPQ) - Brazil through a scholarship to Ms. Meira and by the Savoy Cosmetic Industry SA via the supply of toothpaste.

\section{Conflict of Interest}

The authors declare no conflicts of interest.

\section{Data Availability}

The data used to support the findings of this study can be made available upon request to the corresponding author.

\section{Acknowledgements}

The authors thank Prof. Rosângela Marques Duarte for her collaboration and the Savoy SA for providing the toothpastes for this study

\section{References}

[1] Rølla G, Ogaard B, Cruz RA. Clinical effect and mechanism of cariostatic action of fluoride-containing toothpastes: a review. Int Dent J 1991; 41(3):171-4.

[2] Lippert F. An introduction to toothpaste - Its purpose, history and ingredients. Monogr Oral Sci 2013; 23:1-14. https://doi.org/10.1159/000350456

[3] Cury JA, Tenuta LMA. Evidence-based recommendation on toothpaste use. Braz Oral Res 2014; 28 (Spec No):1-7. https://doi.org/10.1590/S1806-83242014.50000001

[4] Damle SG, Bector A, Damle D, Kaur S. Effect of dentifrices on their remineralizing potential in artificial carious lesions: An in situ study. Dent Res J 2016; 13(1):74-9. https://doi.org/10.4103/1735-3327.174721

[5] Duckworth RM, Jones S. On the relationship between the rate of salivary flow and salivary fluoride clearance. Caries Res 2015; 49(2):141-6. https://doi.org/10.1159/000365949

[6] Chen F, Wang D. Novel technologies for the prevention and treatment of dental caries: a patent survey. Expert Opin Ther Pat 2010; 20(5):681-94. https://doi.org/10.1517/13543771003720491 
[7] Alves VF, Moreira VG, Soares AF, Albuquerque LS, Moura HS, Silva AO, et al. A randomized triple-blind crossover trial of a hydrocolloid-containing dentifrice as a controlled-release system for fluoride. Clin Oral Investig 2018; 22(9):3071-7. https://doi.org/10.1007/s00784-018-2395-0

[8] Fagioli L, Pavoni L, Logrippo S, Pelucchini C, Rampoldi L, Cespi M, et al. Linear viscoelastic properties of selected polysaccharide gums as function of concentration, $\mathrm{pH}$, and temperature. J Food Sci 2019; 84(1):65-72. https://doi.org/10.1111/1750-3841.14407

[9] Kumar A., Lather A, Kumar V, Vikash, Sherawat R, Tyagi V. Pharmacological potential of plant used in dental care: A review. J Herb Drugs 2015; 5(4):179-86.

[10] Wu Y, Ding W, Jia L, He Q. The rheological properties of tara gum (Caesalpinia spinosa). Food Chem 2015; 168:36671. https://doi.org/10.1016/j.foodchem.2014.07.083

[11] Prajapati VD, Jani GK, Moradiya NG, Randeria NP. Pharmaceutical applications of various natural gums, mucilages and their modified forms. Carbohydr Polym 2013; 92(2):1685-99. https://doi.org/10.1016/j.carbpol.2012.11.021

[12] Goswami S, Naik S. Natural gums and its pharmaceutical application. J Sci Innov Res 2014; 3(1):112-21.

[13] Queiroz CS, Hara AT, Paes Leme AF, Cury JA. pH-cycling models to evaluate the effect of low fluoride dentifrice on enamel de- and remineralization. Braz Dent J 2008; 19(1):2 1-7. https://doi.org/10.1590/s0103-64402008000100004

[14] Vieira AEM, Delbem ACB, Sassaki KT, Rodrigues E, Cury JA, Cunha RF. Fluoride dose response in pH-cycling models using bovine enamel. Caries Res 2005; 39(6):514-20. https://doi.org/10.1159/000088189

[15] Dimeski G, Badrick T, St John A. Ion selective electrodes (ISEs) and interferences - a review. Clin Chim Acta 2010; 411(5-6):309-17. https://doi.org/10.1016/j.cca.2009.12.005

[16] Buzalaf MAR, Hannas AR, Magalhães AC, Rios D, Honório HM, Delbem ACB. pH-cycling models for in vitro evaluation of the efficacy of fluoridated dentifrices for caries control: strengths and limitations. J Appl Oral Sci 2010; 18(4):316-34. https://doi.org/10.1590/s1678-77572010000400002

[17] Dehailan LA, Martinez-Mier EA, Eckert GJ, Lippert F. An in vitro investigation of anticaries efficacy of fluoride varnishes. Oper Dent 2019; 44(5):E234-E243. https://doi.org/10.2341/18-040-L

[18] Gavic L, Gorseta K, Borzabadi-Farahani A, Tadin A, Glavina D. Influence of toothpaste pH on its capacity to prevent enamel demineralization. Contemp Clin Dent 2018; 9(4):554-9. https://doi.org/10.4103/ccd.ccd_667_18

[19] Pinto SCTP, Araújo KC, Barbosa JR, Cancio V, Rocha AA, Tostes MA. Effect of dentifrice containing fTCP, CPPACP and fluoride in the prevention of enamel demineralization. Acta Odontol Scand 2018; 76(3):188-94. https://doi.org/10.1080/00016357.2017.1401658

[20] Amaechi BT. Protocols to study dental caries in vitro: pH cycling models. Methods Mol Biol 2019; 1922:379-92. https://doi.org/10.1007/978-1-4939-9012-2_34 